\title{
Investigation of an enameled glass mosque lamp: a 13th-14th-century Mamluk example or 19th-century European version?
}

\author{
Johanna Salvant ${ }^{1}$, Victoria Schussler², Caitlin McKenna ${ }^{2}$, Lisa Bruno ${ }^{2}$, Monica Ganio ${ }^{1}$ and Marc Walton ${ }^{*}$
}

\begin{abstract}
Background: In this study, an enameled glass mosque lamp in the Brooklyn Museum collection is investigated to elucidate the origin and date of production of each of its components - the body, handles, wick-holder, and foot - to establish whether the lamp was produced during the Mamluk period (13th-14th century) or is a 19th-century European creation.

Results: Using X-ray fluorescence spectrometry and scanning electron microscopy with energy dispersive X-ray spectrometry (SEM-EDS), the body, handles, and wick-holder were found to exhibit identical composition. The lamp's foot, however, presents a dissimilar composition, one significantly richer in sodium, magnesium, and potassium. The matrix compositions, colorants, and opacifiers of the body's enamel decorations were characterized by SEM-EDS and Raman spectroscopy analyses and compared with Mamluk and 19th-century production.

Conclusions: The lamp's body, handles, and wick-holder were produced using the same type of glass, one likely incorporating a plant ash flux typical of medieval Islamic glass. Materials composing the body's enamel decorations are consistent with Mamluk production. The foot's distinct composition indicates that it is a later addition to the object. Combining the analytical, stylistic, and historical evidences, this glass lamp can now be identified as a Mamluk example, one of few comprising an integral wick-holder. The presence of a wick-holder is discussed and connected to the small size of the lamp. Details informing understanding of the lamp's manufacture are also included. The implications of these new findings on the object's conservation treatment and display are discussed in the context of the upcoming reinstallation of the Arts of the Islamic World gallery at the Brooklyn Museum.
\end{abstract}

Keywords: Mamluk, Islamic glass, Mosque lamp, Enamel, XRF, SEM-EDS, Raman spectroscopy

\section{Introduction}

First made during the overlapping Ayyubid (c. 1171-1260 C.E.) and Mamluk periods (c. 1250-1517 C.E.) in Egypt and the Levant, enameled glass mosque lamps have become closely associated with the history of Islamic art as presented in museums [1]. Carboni [1] describes a mosque lamp as "a lighting device made for a devotional building in the Islamic world, such as a mosque, a madrasa [religious school], a tomb or mausoleum, or a khanaqa [hostel]." However, the archaeological record

\footnotetext{
*Correspondence: marc.walton@northwestern.edu

${ }^{1}$ Center for Scientific Studies in the Arts, Northwestern University, 2145

Sheridan Road, Evanston, IL 60208, USA

Full list of author information is available at the end of the article
}

and literary sources suggest that mosque lamps developed in domestic, rather than religious, contexts [1]. Mamluk mosque lamps usually take the form of a vaseshaped vessel with a flattened globular body and a wide, funnel-shaped neck. Two types of feet are common: either a flaring cone or a simple circular disk. Generally termed a "lamp," these vessels actually functioned as "lampshades" that contained a smaller glass vessel, usually a saucer or tube, which held the oil and wick to light the lamp [1]. Suspended by long metal chains hooked to the vessels' integral glass handles, these lamps hung from ceilings in their original architectural contexts.

Collecting, studying, and copying Islamic art from earlier centuries became popular in Europe during the late

\section{Springer}

(C) 2016 Salvant et al. This article is distributed under the terms of the Creative Commons Attribution 4.0 International License (http://creativecommons.org/licenses/by/4.0/, which permits unrestricted use, distribution, and reproduction in any medium, provided you give appropriate credit to the original author(s) and the source, provide a link to the Creative Commons license, and indicate if changes were made. The Creative Commons Public Domain Dedication waiver (http://creativecommons.org/ publicdomain/zero/1.0/) applies to the data made available in this article, unless otherwise stated. 
19th century. Known to Europeans since the time of their production via extensive trade between the Mamluks and the Venetians, these 13th-14th-century Mamluk mosque lamps were of particular interest to 19th-century collectors due to their "exotic" and luxurious appearance [2]. Major collections of gilded and enameled glass were formed in the 19th century; however, these collections were often beset by confusion or misattribution of the individual pieces therein [3]. In particular, French glassmaker Philippe-Joseph Brocard (1831-1896), inspired by enameled glass mosque lamps from the Mamluk period, collected such lamps and was especially gifted at creating successful facsimiles of Islamic enameled glass [4]. Many of Brocard's lamps survive in museum collections. Besides crafting unique artworks in the style of Islamic enameled glass, Brocard is also known to have restored enamels on genuine medieval examples [5]. It is not surprising, then, that such 19th-century creations could be mistaken for medieval Islamic objects, and vice versa, without detailed technical and material analysis.

This article focuses on an enameled glass lamp (accession number 21.484-Fig. 1a) initially acquired by the Brooklyn Museum in 1921 from the collection of William $\mathrm{H}$. Herriman. Two other Islamic-style mosque lamps, including one signed "Brocard, Paris, June 1871," were also part of the Herriman bequest. Examples from either era that lack identifying inscriptions or signatures often confuse and complicate the dating and attribution of both medieval Islamic and 19th-century European enameled glass, even in today's museum collections. Differing scholarly assessments cited in Brooklyn Museum records had suggested that the lamp (21.484) might be of later European production based on both stylistic considerations and the presence of a tubular glass wick-holder (Fig. 1b), or that the broken foot might be a later addition. The foot, which was historically associated with the lamp, was adhered to the object in 1970.

Analytical studies of enameled glass vessels in the literature [6-11] demonstrate significant compositional differences between Mamluk and 19th-century production. Building on this previous research, here we present results of analysis undertaken using XRF, SEM-EDS, and Raman spectroscopy to investigate the lamp's materials. This paper also addresses the implications of the research for the lamp's conservation treatment, future display, and didactic interpretation in the Museum's forthcoming reinstallation of its permanent-collection gallery, planned to open in 2017.

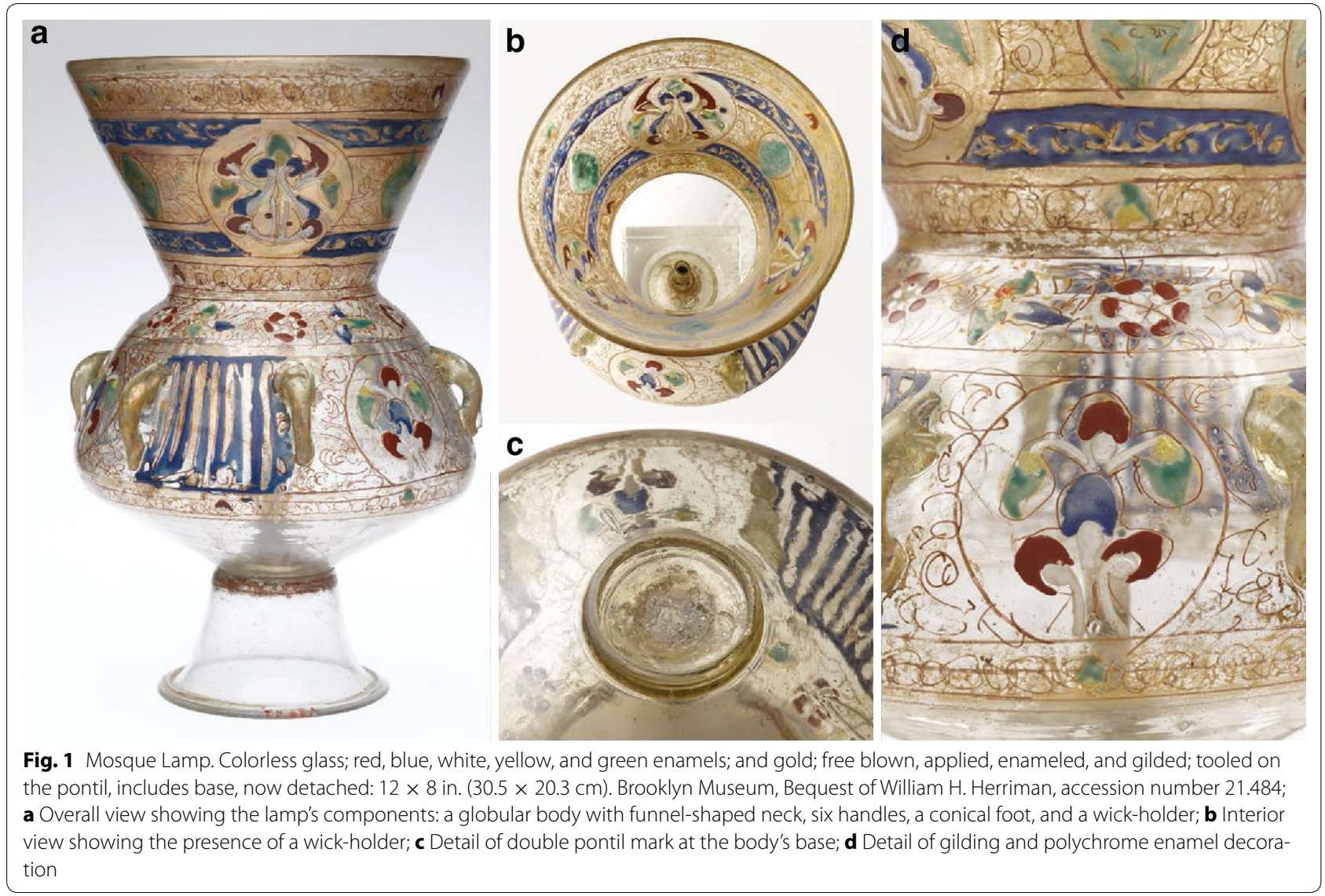




\section{Experimental}

\section{Sampling and sample preparation}

The 1970 adhesive join between the body and foot was reversed with ethanol, enabling sampling of the bulk glass. Samples of the colorless glass, each measuring a few hundred microns in width, were taken from the lamp's main components-the body, the wick-holder, and the foot-using a diamond-grit cutting wheel. In addition, a smaller fragment was taken from each colored enamel (red, blue, white, yellow, and green). The samples were embedded in epoxy resin and polished as crosssections. Cross-sections were examined with a Nikon Eclipse MA200 polarized light microscope (LM). Optical images were captured using an attached Nikon digital sight DS-FI2 camera. Cross-sections were carbon coated for the SEM-EDS analyses.

\section{XRF spectrometry}

XRF analyses were initially performed in situ on the glass lamp using an ELIO portable X-ray fluorescence spectrometer (XGLab), equipped with a rhodium tube and $1 \mathrm{~mm}$ spot size. An integrated CCD camera and two laser pointers allow perfect focus on the desired region of interest. Each point analysis was performed twice on the same spot, one in atmospheric conditions at $40 \mathrm{kV}$ and $100 \mu \mathrm{A}$ and one under helium flux at $20 \mathrm{kV}$ and $200 \mu \mathrm{A}$, to improve the sensitivity of detection of light elements ( $Z$ below 15). Collection time of each analysis was $300 \mathrm{~s}$. Point analyses were performed on multiple areas of the colorless glass of each accessible part of the lamp (body, handles, and foot) and of the colored enamels from the neck and body (red, blue, white, yellow, and green). A set of six certified reference materials (National Institute of Standards and Technology NIST 610, NIST 612, NIST 620, and NIST 1830; Corning Museum of Glass Corning B and Corning C) was also analyzed in the same conditions.

\section{SEM-EDS}

SEM-EDS analyses were performed on the carboncoated cross-sections to further investigate the glass matrix composition, especially regarding the detection of light elements, and the nature and distribution of the inclusions within the enamels. Backscattered electron (BSE) images were acquired using a Hitachi S-3400 N-II in high vacuum mode, equipped with an Oxford INCAxact SDD energy-dispersive spectrometer. The accelerating potential was $20 \mathrm{kV}$. EDS analyses were performed with a working distance of $10 \mathrm{~mm}$. Six EDS analyses with a total acquisition time of $300 \mathrm{~s}$ were performed in different areas of the colorless glass matrices of the body, the wick-holder, and the foot. For the enamels, two or three EDS analyses each with a total acquisition time of $300 \mathrm{~s}$ were performed in the matrix, while an acquisition time of $30 \mathrm{~s}$ was used for the analysis of the inclusions.

\section{Raman spectroscopy}

Raman spectroscopy was performed on the enamel sample cross-sections using a Jobin-Yvon Horiba LabRam HR Evolution spectrometer, equipped with a high efficiency thermal cooled CCD detector, a confocal microscope (Olympus), a holographic notch filter, and with 1800 grooves/mm grating. Raman spectra were recorded under a confocal microscope with a $100 \times$ objective focusing the $532 \mathrm{~nm}$ line. Measurements were performed using a laser with a maximum output power of $50 \mathrm{~mW}$, and appropriate neutral density filters were used such that the power at the sample was kept at a maximum of $2.5 \mathrm{~mW}(0.5 \mathrm{~mW}$ for the blue, $1.6 \mathrm{~mW}$ for the red and green, and $2.5 \mathrm{~mW}$ for the white and yellow enamels). The pinhole of the confocal microscope was kept at $50 \mu \mathrm{m}$. Spectra were collected with repeated accumulations (2-3), each of 15-150 s (15 s for the yellow, $30 \mathrm{~s}$ for the blue, $60 \mathrm{~s}$ for the white, and $150 \mathrm{~s}$ for the red and green enamels). Data acquisition and spectral treatment were carried out with the commercially available software program LabSpec 6 (HORIBA Scientific).

\section{Laser ablation inductively coupled plasma mass spectrometry (LA-ICP-MS)}

LA-ICP-MS analyses were performed on the red and blue enamel cross-sections using a Varian ICP-MS and a New Wave UP213 laser. A single point analysis mode was used, with a laser beam diameter of $30 \mu \mathrm{m}$ operating at $100 \%$ of the laser energy $(0.2 \mathrm{~mJ})$ and at a pulse frequency of $20 \mathrm{~Hz}$. The experimental procedure has been previously described in detail [12]. A set of four certified reference materials (NIST 610 and NIST 612; Corning Museum of Glass Corning B and Corning D) was also analyzed in the same conditions to calculate the concentrations of major, minor, and trace elements. Due to the small size of the samples compared to the beam size, only a single replicate could be performed on each fragment, and the contribution of the embedding resin cannot be excluded. For these reasons, the LA-ICP-MS measurements are not considered reliable for quantitation, but have been used to inform and support interpretation of the other analyses. The LA-ICP-MS analyses were not performed on further samples to preserve the full integrity of the other cross-sections.

\section{Results}

\section{Object description}

Measuring approximately $29 \mathrm{~cm}$ in height and $19 \mathrm{~cm}$ in diameter at its maximum dimensions, the lamp in the Brooklyn Museum's collection (Fig. 1a) is of relatively 
small size as compared to many Mamluk mosque lamps [1]. Free-blown of colorless glass, the lamp comprises the typical globular body and conical neck. Six applied handles or suspension loops protrude from the vessel's wall. The bulk glass of the lamp's body comprises many small bubbles and granular inclusions, as well as large and elongated bubbles. Subtle concentric circular ridges mark the vessel's underside, intimating the object's freeblown manufacture. The body's base appears to comprise a double pontil mark, with a larger scar partially filled by additional glass from a second pontil, suggesting that the object was reintroduced into the furnace during manufacture (Fig. 1c). Uncommon among Mamluk lamps, an upright tubular wick-holder appears within the vessel at the base of the lamp's body (Fig. 1b).

Gilding, fine lines in thin red enamel, and thicker polychrome enamels in red, blue, white, yellow, and green decorate the Brooklyn Museum's lamp (Fig. 1d). Floral and abstract motifs cover its neck and body, which is inscribed with the Arabic phrase "I $|\varepsilon| J_{p}$ " [al-" alim/the wise] in thuluth script repeated three times. The area around the inscription is covered with floral and fruit forms. The vessel's underside and interior are undecorated with the exception of three green pointed ellipses on the neck of the lamp (Fig. 1b).

Also free-blown of nearly colorless glass, the foot currently associated with the lamp comprises a flaring conical shape with a folded rim (Fig. 1a). The foot's break edge has been heavily ground down, and the break edges of the body and foot do not meet, suggesting that the foot may not be original to the rest of the lamp.

\section{Comparison of the colorless vessel glass among the lamp's components}

XRF analysis was performed on the colorless glass comprising the body, handles, and foot (Fig. 2a). The body and handles exhibit identical responses to XRF, with high amounts of silicon and calcium and smaller amounts of potassium, manganese, and iron. Gold was also detected in areas with more intact gilding. The colorless glass of the foot includes the same elements (silicon, calcium, potassium, iron, and manganese), but with a significantly higher amount of potassium as compared to the body and handles.

Six EDS analyses were performed on cross-sections of colorless glass samples from the body, wick-holder, and foot to further compare their compositions and to improve the detection of light elements ( $\mathrm{Z}$ below 15). The colorless glass from the different parts of the lamp all have a soda-lime-silica glass $\left(\mathrm{Na}_{2} \mathrm{O}-\mathrm{CaO}-\mathrm{SiO}_{2}\right)$ composition, decolored by manganese oxide $(\mathrm{MnO})$ and with similar amounts of aluminum ( $\mathrm{Al})$, phosphorous $(\mathrm{P})$ and chlorine $(\mathrm{Cl})$ relatively to their respective silicon
(Si) content. To compare alkali contents among samples (Fig. 2b), the Si-normalized intensity of the K-alpha X-ray peaks of sodium $(\mathrm{Na})$, potassium $(\mathrm{K})$, and magnesium (Mg not shown in Fig. 2b) for each EDS spectrum were plotted as box-and-whisker plots. While the body and the wick-holder exhibit identical soda, potash $\left(\mathrm{K}_{2} \mathrm{O}\right)$, and magnesia $(\mathrm{MgO})$ contents, the foot exhibits a different composition, significantly richer in alkali.

\section{Characterization of the enamels}

Following preliminary in situ XRF analysis, complementary analyses (SEM-EDS and Raman spectroscopy) were performed on enamel samples to investigate each color's glass matrix microstructure and composition, as well as the nature of the opacifiers and colorants.

\section{Enamel glass matrix composition}

EDS spectra of the glass matrices of the different enamels are shown in Fig. 3. All exhibit a similar composition, with high amounts of silica, significant amounts of soda, some lime, magnesia, and potash, and small amounts of alumina $\left(\mathrm{Al}_{2} \mathrm{O}_{3}\right)$, suggesting the enamels are soda-limesilica glass. However, significant differences are observed in the amount of lead detected. Similarly to the body's colorless vessel glass, no lead or only minor amounts of lead were detected by XRF and EDS in the matrices of the red and blue enamels, respectively. Conversely, higher amounts of lead were identified in the matrices of the white, yellow, and green enamels.

Comparing the major elements constituting each glass matrix (Fig. 3), the matrices of the red and blue enamels exhibit EDS profiles very similar to that of the object's vessel glass, suggesting that very similar types of glass were used to produce the red enamel, blue enamel, and the bulk glass. LA-ICP-MS analyses indicate approximately $3-4 \mathrm{wt} \%$ magnesia and potash in the red and blue enamels. The white, yellow, and green enamel matrices are also soda-lime-silica glass, but enriched in lead.

Raman spectra of the glass matrices of the different enamels are shown in Fig. 4. The red (Fig. 4c) and blue (Fig. 4f) enamels present a broad band at around $1100 \mathrm{~cm}^{-1}$, corresponding to the $\mathrm{Si}-\mathrm{O}$ stretching band typical for a soda-silica glass [11]. In contrast, the broad $\mathrm{Si}-\mathrm{O}$ stretching band is observed at lower positions for the other colors, around $1050 \mathrm{~cm}^{-1}$ in the white enamel (Fig. 4i), and at around $980 \mathrm{~cm}^{-1}$ in the yellow (Fig. 4l) and green (Fig. 4o) enamels. The presence of fluxes, such as lead oxide $(\mathrm{PbO})$, in the glass composition modifies the network of $\mathrm{SiO}_{4}$ tetrahedra, impacting the Raman signature: a broad $\mathrm{Si}-\mathrm{O}$ stretching band at lower wavelength, around $950-960 \mathrm{~cm}^{-1}$, has been identified as characteristic of lead-containing glasses [13]. The position of the $\mathrm{Si}-\mathrm{O}$ stretching band observed in the white, yellow, and 


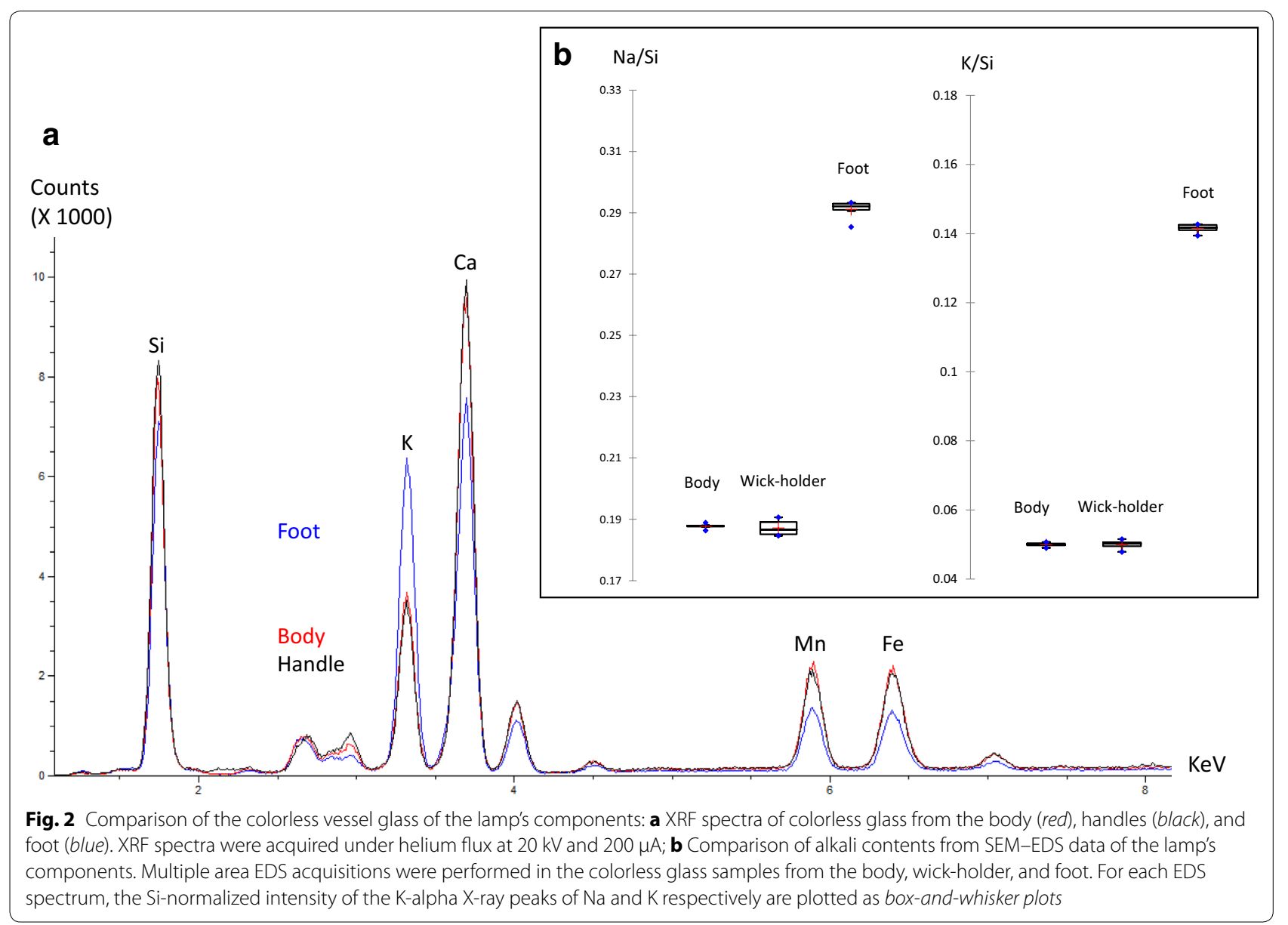

green enamels constitutes another indication of these enamels' enrichment in lead oxide, probably more moderate in the white enamel based on the intermediate position of the band.

\section{Colorants and opacifiers}

\section{Low-lead enamels}

(i) Red enamel SEM-EDS analysis of the red enamel reveals fine iron-rich inclusions of small size (c. $2 \mu \mathrm{m}$ for the largest) that are heterogeneously distributed within the enamel (Fig. 4b); the inclusions surround the glass particles, which measure approximately $10-40 \mu \mathrm{m}$. Large bubbles are also observed in the red enamel matrix (Fig. 4a, b). These iron-rich inclusions present the characteristic Raman signature of hematite $\left(\alpha \mathrm{Fe}_{2} \mathrm{O}_{3}\right)[14,15]$ (Fig. 4c) and are responsible for the red color of the enamel.

The thinner red enamel also decorating the body of the lamp could not be sampled; however, XRF detected higher amounts of iron along these red lines as compared to the bulk glass. This suggests that an iron-rich compound, likely hematite, is also responsible for the red color of this enamel.

(ii) Blue enamel LM and BSE images show that the blue enamel contains relatively large and angular blue inclusions with a size of up to $10 \mu \mathrm{m}$ (Fig. 4d, e). EDS analyses indicate that these inclusions consist of silica together with higher levels of aluminum, sulfur, and sodium than those of the surrounding matrix. The presence of cobalt can indicate the use of cobalt oxide as a blue colorant; however, no cobalt was detected by SEM-EDS in either the glass matrix or inclusions of the blue enamel. LA-ICP-MS analysis did detect trace cobalt, in the range of about 1-10 ppm, the very low concentration confirming that cobalt oxide can be ruled out as a blue colorant in the blue enamel. Raman spectra of these inclusions exhibit the characteristic resonance of $\mathrm{S}_{3}{ }^{-}$and $\mathrm{S}_{2}{ }^{-}$multiatomic ions (a very strong band at $548 \mathrm{~cm}^{-1}$ with weak bands at 258 and $290 \mathrm{~cm}^{-1}$, and a weak band at $588 \mathrm{~cm}^{-1}$, respectively) (Fig. 4f), and appear identical to the Raman signature of lazurite $\left(\mathrm{Na}_{8}\left[\mathrm{Al}_{6} \mathrm{O}_{24}\right] \mathrm{S}_{\mathrm{n}}\right)[11,16]$, the mineral responsible for the blue color of the semi- 


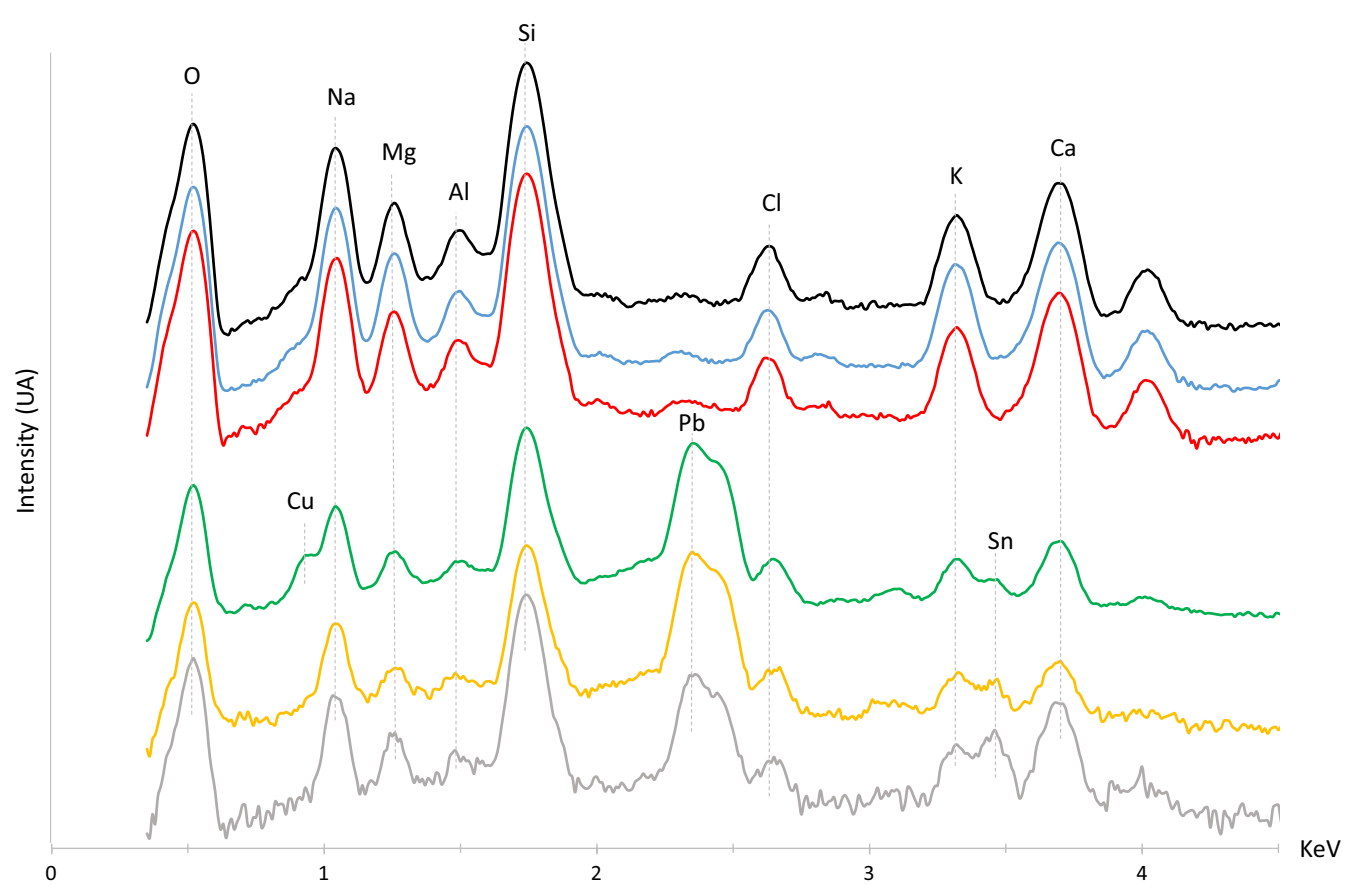

Fig. 3 Comparison of EDS spectra of the polychrome enamel samples' glass matrices (corresponding color, white enamel in gray) and of the body bulk glass sample (black)

precious stone lapis lazuli. This has been attributed in the literature to the use of finely crushed lapis lazuli as the blue coloring agent in Islamic blue enamels $[7,8,10,11]$. Interestingly, in the sample from the Brooklyn Museum's lamp, weak Raman signatures for lazurite and sulfur were detected in areas of the blue enamel matrix free of blue particles. An EDS profile tracing changes in sulfur content through a colored particle into the enamel matrix indicates that sulfur content drops rapidly with increasing distance from a blue inclusion; however, a small amount of sulfur is clearly present in the enamel matrix itself.

A white inclusion measuring approximately $15 \mu \mathrm{m}$ long was observed at the interface of the blue enamel matrix with the colorless glass. This inclusion contains more calcium and magnesium and less sodium and potassium than the blue enamel matrix, and also contains tin-rich particles not present in the blue enamel matrix. A single iron-rich red inclusion, likely hematite, was also identified within the blue enamel matrix. Corresponding to materials from other colored enamels, these inclusions may constitute contaminants that were unintentionally mixed with the blue enamel during application.

A small fragment of gilded colorless glass from the body of the lamp was incidentally sampled together with the blue enamel (Fig. 4d, e). These flake-shaped samples of the lamp's gilding measure approximately $400-800 \mathrm{~nm}$ thick.

Lead-rich enamels

(i) White enamel LM and BSE images of the sample (Fig. 4g, h) reveal a bubbly texture and that the white enamel is intimately mixed with the adjacent red enamel, appearing light gray and dark gray, respectively, in the BSE image. Tin-rich white inclusions, ranging in size from less than $1 \mu \mathrm{m}$ to approximately $6 \mu \mathrm{m}$, are observed in the white enamel matrix by SEM-EDS (Fig. 4g, h). The Raman spectra of these inclusions present a doublet at 635 and $779 \mathrm{~cm}^{-1}$ (Fig. 4i), characteristic of tin oxide (cassiterite $\mathrm{Sn}_{2} \mathrm{O}$ ) [11]. The tin oxide particles act as both the opacifier and the white colorant. Likely an accidental addition, a single blue inclusion measuring approximately $5 \mu \mathrm{m}$ was observed in the white enamel sample. This inclusion was identified as lazurite by Raman spectroscopy.

(ii) Yellow enamel The yellow enamel matrix contains light yellow inclusions appearing white in BSE images. These inclusions vary in size, the largest being approximately $10 \mu \mathrm{m}$ (Fig. 4j, k, p), and contain high amounts of lead and some tin. The Raman spectra of these inclusions exhibit characteristic bands of the cubic form of lead-tin yellow (lead-tin yellow 


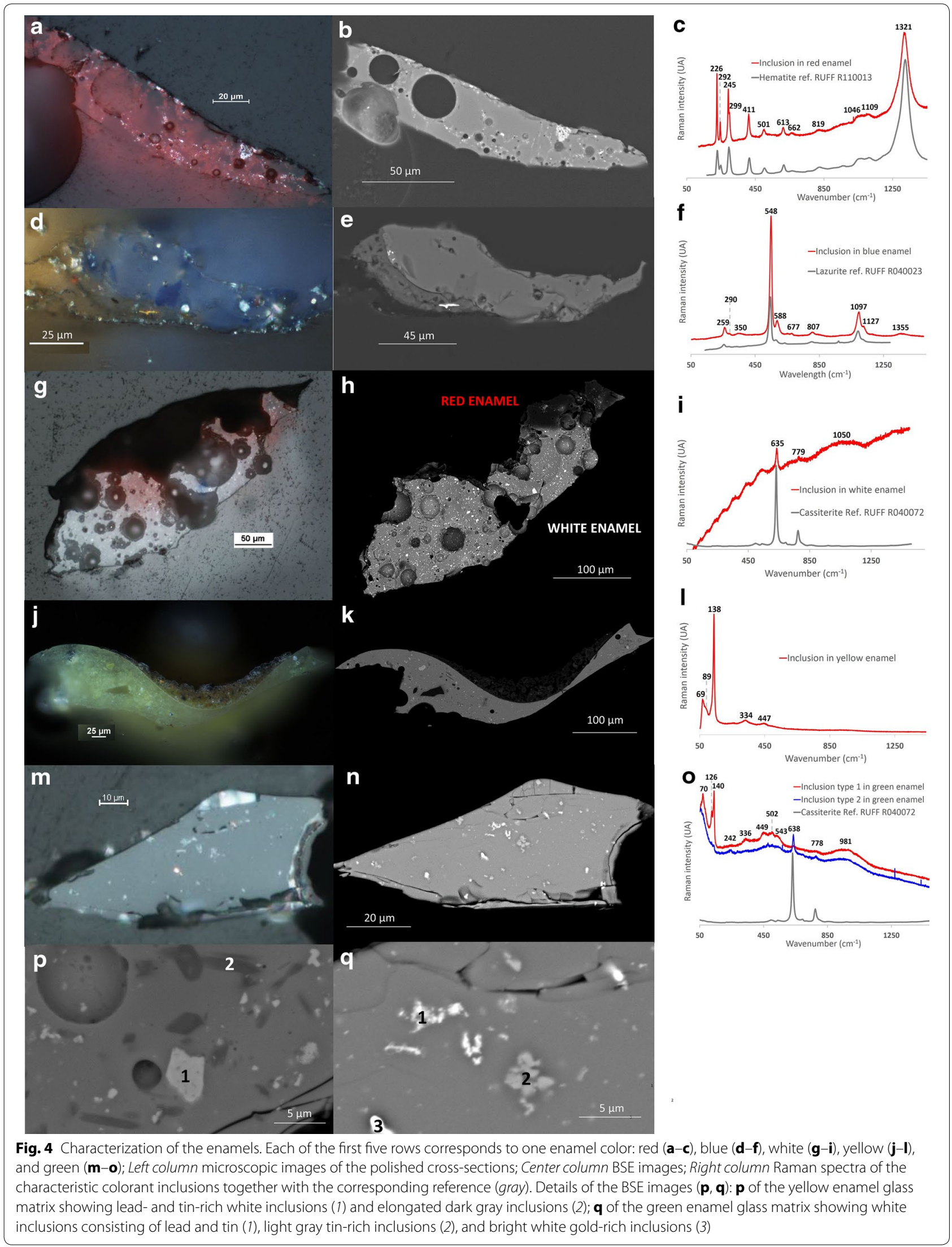


type II, $\left.\mathrm{Pb}_{2} \mathrm{Sn}_{1-\mathrm{x}} \mathrm{Si}_{\mathrm{x}} \mathrm{O}_{3}\right)[17,18]$, with a very strong band at $138 \mathrm{~cm}^{-1}$, weak broad bands at 334 and $447 \mathrm{~cm}^{-1}$, and a medium-intensity band at $69 \mathrm{~cm}^{-1}$ (Fig. 4l). The lead-tin yellow type II particles serve as both the opacifier and the colorant of the yellow enamel.

In addition, the yellow enamel matrix contains a single large translucent and angular inclusion (c. $25 \mu \mathrm{m}$ ) appearing black in BSE images (Fig. 4k) and corresponding to unreacted quartz based on Raman spectroscopy analysis. Several darker gray inclusions, most having elongated shapes, are also visible in the BSE image of the enamel matrix (Fig. 4p). EDS analyses indicate that these inclusions are richer in calcium as compared to the surrounding glass matrix, and are likely feldspars (tectosilicates minerals) introduced along with the sand raw material. Finally, a small number of round gold inclusions were also detected, one of which also includes traces of silver. The inclusions may pertain to the yellow enamel; however, the small number of these gold inclusions suggests that they likely constitute contaminants from the object's gilding.

(iii) Green enamel SEM-EDS analysis identified two main types of inclusions (size up to c. 1-2 $\mu \mathrm{m}$ ) in the green enamel matrix (Fig. 4m, n, q). The first type, appearing white in BSE images (Fig. 4q) and with high lead and tin content in SEM-EDS spectra, were confirmed to be lead-tin yellow type II by Raman spectroscopy analysis (Fig. 4o) [17, 18]. The second type are light gray (Fig. $4 \mathrm{q}$ ), tin-rich inclusions with the characteristic Raman signature of tin oxide [11]. These lead-tin yellow and tin oxide inclusions opacify the green enamel. Moreover, the green enamel matrix is enriched in copper (Fig. 3), which, in combination with the lead-tin yellow particles, produces the green color. Additionally, two gold inclusions with traces of silver (Fig. $4 \mathrm{q}$ ) were identified in the green enamel matrix by SEM-EDS analysis. As with the yellow enamel, the origin of these gold inclusions is unknown; however, the small number of gold inclusions suggests contamination rather than deliberate addition.

\section{Discussion}

Following its arrival at the Brooklyn Museum in 1921, the lamp has been assigned many different dates and places of production. Shifts in museum organization and the scholarly vocabulary used to describe "Islamic" artproblematic in itself-account for some geo-cultural discrepancies; however, no early attribution dates the lamp to the Mamluk period. In 1991, Dr. Rachel Ward, then Keeper at the British Museum, noted the lamp's glass "funnel," or wick-holder; such wick-holders were known to her in medieval Persian lamps, but not in those made in Mamluk Egypt and Syria. Ward also regarded the handles' aesthetic as characteristic of 19th-century France, despite their careful integration with the object's decorative scheme. In 1992, Dr. Stefano Carboni, former Curator at the Metropolitan Museum of Art, instead thought the lamp might constitute a 13th- or 14th-century example, one of the few known to him with an intact wickholder. Carboni doubted a 19th-century overall date of production, but suggested that the flared pedestal foot could be a later addition based on the fine bubbles of the foot's bulk glass as compared to the body.

Current observations also inform the discussion regarding the lamp's production date, as well as the relationship of the foot to the rest of the vessel. The double pontil mark visible on the base of this lamp is characteristic of vessels reintroduced into the furnace on a pontil rod to fuse gilding and enamels, a technology consistent with Mamluk production, as opposed to kiln-firing of enamels, a technique not practiced until the 19th century [19]. Although both edges have been partially ground down, the broken edges of the body do not meet or match those of the foot; the diameter of the body's broken edge fits entirely within that of the foot. As compared to other Mamluk era lamps, the foot seems disproportionate to the body. Additionally as opposed to the enamels decorating the lamp's body, red and gold-colored paints, cold-applied and unfired, decorate the top edge of the foot, perhaps an attempt to visually integrate these two sections of the object and to cover an adhesive repair. The date of the paint application is, however, unknown.

The analytical results presented here support Carboni's hypothesis. While the body, the handles, and the wick-holder exhibit identical glass compositions, the foot presents a dissimilar and distinct bulk glass composition with significantly higher amounts of alkali. These results, together with close examination of the object, confirm that the handles and the wick-holder are original to the object and that the foot constitutes a later addition.

Typical of Islamic glass production from the 9th century onward [20-22], the glass used to produce the body, the handles, and the wick-holder was qualitatively identified as soda-lime-silica glass with significant amounts of magnesia and potash, probably on the order of 3-4 wt\% as detected by LA-ICP-MS in the red and blue enamels and consistent with the use of a halophytic plant ash flux $[20,21,23]$. Compositionally distinct from Mamluk glass described in the literature [6-10], 19th-century European glass vessels comprise various compositions, including soda-lime-silica glass but generally with lower amounts of magnesia and potash as compared to Mamluk glass [10] and mixed alkali glass $[8,11]$. Commonly used as a 
decoloring agent in the Mamluk period [6-10], manganese oxide decolorizes the vessel glass of the Brooklyn Museum's lamp. However, the use of small amounts of manganese oxide is also reported in some 19th-century productions, the reduced need for a decoloring agent likely indicating the use of more highly purified raw materials in formulating the bulk glass melt $[8,10]$. Quantification of manganese oxide present in the Brooklyn Museum's lamp would be necessary to further evidence Mamluk production.

The lamp's enamel matrices and colorants are also consistent with Mamluk production [6-11]. The Brooklyn Museum's lamp comprises both low-lead and leadrich soda-lime-silica enamel matrices, the lead content depending on the enamel color. Conversely, all 19thcentury enamel colors are identified in the literature as lead-rich $[8,10,11]$. Further, the colorants and opacifiers identified, summarized in Table 1, correspond to those used in the Mamluk period. Sulphur-bearing sodium alumino-silicate particles color the blue enamel. Rather than the lead arsenate $\left(\mathrm{Pb}_{3}\left(\mathrm{AsO}_{4}\right)_{2}\right)$ identified in 19th-century objects, fine tin oxide particles opacify the white enamel. The yellow and green enamels are opacified by lead stannate, which is dissimilar to the colorants and opacifiers found in later European production, such as uranium trioxide $\left(\mathrm{UO}_{3}\right)$ or lead chromate $\left(\mathrm{PbCrO}_{4}\right)$ for the yellows and chromium-based compounds in the greens.

The Brooklyn Museum's lamp includes a tubular wick-holder attached to the interior base. Carboni [1] describes an integral glass tube as "the most common way to create a wick-holder on pre-Mamluk objects." Codified by the 13th century, the definitive form of the Mamluk mosque lamp-a globular vase with a flaring neck-utilizes a shallow dish suspended within the lamp, which replaced the narrow tubular wick-holders of earlier examples [1,24]. Interestingly, a mid-13th-century lamp in the Victoria and Albert Museum illustrates a progression of form, combining an integral tubular wick-holder with the formal elements of later Mamluk examples, but without the characteristically extensive gilding and enameling [24].

Few Mamluk-period mosque lamps with tubular wickholders are known; however, Carboni [1] has published two such lamps with complete or fragmentary tubular wickholders similar to the one in the Brooklyn Museum example. Now in the collection of the Museum of Islamic Arts, Qatar, one of these lamps (cat. no. 5) dates to c. 1300-1350 C. E., while the other (cat. no. 7) is ascribed to the reign of Sultan al-Nasir al-Hasan ibn Muhammad Nasir al-Din Nasir al-Din (c. 1350-1365 C. E.) or shortly thereafter [1]. Both mosque lamps measure about $27 \mathrm{~cm}$ in height and $18.5 \mathrm{~cm}$ in maximum diameter and are, like their Brooklyn Museum counterpart, relatively small as compared to most Mamluk mosque lamps. The collection of The Metropolitan Museum of Art includes another mosque lamp (c. 1325), measuring $27.6 \mathrm{~cm}$ in height and $20.8 \mathrm{~cm}$ in diameter, with an intact tubular wick-holder [25]. The use of integral tubular wick-holders in these lamps may relate to a practical decision, rather than reflecting a chronological progression [1]. The Brooklyn Museum's lamp is, then, one of a group of relatively few Mamluk lamps known with this type of wick-holder, the dimensions of which support Carboni's supposition that integral tubular wick-holders were used in lamps of relatively small diameter even during the Mamluk period when larger contemporaries were fitted with saucers suspended by chains.

Distinct from that of the rest of the object, the foot's chemical composition indicates that it was made with a glass significantly richer in soda, potash, and magnesia, due to the use of a dissimilar flux. The differences in composition suggest that the foot was produced in a distinct place and/or time as compared to the other parts of the lamp and confirms that the foot is a later addition to the object.

\section{Manufacture}

The analytical results presented above not only clarify the lamp's production era and the relationship of the body to the foot, they also inform our understanding of

Table 1 Summary of colorants identified in the lamp (21.484) and comparison with the literature

\begin{tabular}{|c|c|c|c|}
\hline \multirow[t]{2}{*}{ Enamel color } & \multicolumn{3}{|l|}{ Colorant and/or opacifier } \\
\hline & Glass lamp 21.484 & Mamluk enameled glass vessels $[6-8,10,11]$ & $\begin{array}{l}\text { 19th-century European enameled glass } \\
\text { vessels in Islamic style }[8,10,11]\end{array}$ \\
\hline Red & Hematite & Hematite & Hematite \\
\hline Blue & Lazurite & Lazurite or, less commonly, cobalt oxide & Cobalt oxide \\
\hline White & Tin oxide & Tin oxide or, less commonly, calcium phosphate & Lead arsenate \\
\hline Yellow & Lead-tin yellow type $\|$ & $\begin{array}{l}\text { Lead-tin yellow (most common) and/or lead anti- } \\
\text { monate, tin oxide sometimes also present }\end{array}$ & $\begin{array}{l}\text { Lead antimonate, uranium trioxide, or lead } \\
\text { chromate }\end{array}$ \\
\hline Green & $\begin{array}{l}\text { Lead-tin yellow type } I I \text { and tin } \\
\text { oxide + copper }\end{array}$ & $\begin{array}{l}\text { Lead-tin yellow (most common) and/or lead anti- } \\
\text { monate + copper, tin oxide sometimes also present }\end{array}$ & $\begin{array}{l}\text { Chromium-based compounds (chromium } \\
\text { oxide or lead chromate), in some cases } \\
\text { mixed with cobalt }\end{array}$ \\
\hline
\end{tabular}


manufacturing technology and sequence. Further, this analysis aids in the reconciliation of observations made throughout this object's years in the Brooklyn Museum collection.

Reserved medallions of undecorated glass frame the handles of many published Mamluk lamps. Because of the high temperatures associated with furnace firing, Gudenrath [19] and others suggest that vessel blanks were decorated and fired before bits like handles were added to avoid handles' slumping or deforming a vessel body. Presumably to facilitate the handles' addition, enamels were applied leaving some undecorated space around the handles' intended attachment sites. However, the handles of the Brooklyn Museum's lamp are gilded and close examination reveals that gilding and enamels decorating the body pool around and slightly over the edges of the handles' attachment points. These observations indicate that the handles were already in place when the blank was decorated and fired. Since analytical data has shown the body, handles, and enamels of this vessel to be consistent with Mamluk production, this technological detail speaks to the variety of manufacturing practices and addresses Ward's opinion of the handle's aesthetic as "19th-century."

Visual inspection of the Brooklyn Museum's lamp reveals the order in which its decorative materials were applied (Fig. 1d). Thin red enamel lines overlap gilding, while thicker polychrome enamels overlap both gilding and thin red enamel, meaning that the gilding was applied first, followed by the thin red enamel, and finally the thicker polychrome enamels. Close examination of the gilding and identification of a few gold flakes within the colorless glass indicate that the gold was finely ground to less than one micrometer thick and applied in a medium, rather than as gold leaf. Gold particles could be suspended in a medium, such as a mixture of water and gum Arabic or a light oil, and applied to the glass surface with a brush or stylus before firing [26, 27].

Made from finely crushed glass suspended in a liquid medium [19], likely oil-based, the enamels were applied probably using a brush or a reed pen [24]. Two distinct preparation methods create two types of enamels: coldmixed and pre-fritted [7, 19]. Made by mixing colorless glass with pigments, cold-mixed enamels are directly applied to the glass vessel without prior firing $[7,19]$. Conversely, making pre-fritted enamels includes the additional step of preparing a frit-a colored glass obtained by melting together a mixture of fluxes and pigments-that is then crushed and applied to the glass vessel [7, 19].

The red enamels studied here were clearly prepared as cold-mixed enamels as evidenced by backscattered SEM images (Fig. 4b), in which outlines of the colorless glass particles are visible and surrounded by red pigment. The red enamels were made by mixing hematite with crushed colorless glass, similar to the vessel glass, without prior firing. Similarly heterogeneous distribution patterns of hematite within the enamel matrix have been observed in 13th- and 14th-century Islamic red enamels [7].

The white, yellow, and green enamels present relatively homogeneous microstructure: the constituent compounds seem to have largely reacted together, suggesting these colors were prepared as pre-fritted enamels. The presence of unreacted quartz, feldspars, and cubic lead-tin yellow particles confirms the hypothesis that the yellow enamel was produced starting with a frit made by mixing glass raw materials with lead and tin oxides. When melted together in presence of silicates, lead and tin oxides form the cubic form of lead-tin yellow $[28,29]$. The green enamel, also exhibiting cubic lead-tin yellow particles, was produced in the same way, but with the addition of a copper source. However, the green enamel was probably made with a higher silica content or heated at a higher temperature than the yellow, leading to the recrystallization of the cassiterite particles [29] observed in the green matrix. In the white enamel, the micrometric size of homogeneously distributed cassiterite particles combined with the presence of significant lead content in the matrix support the hypothesis that the white enamel was pre-fritted, allowing for the recrystallization of cassiterite particles. The firing of the $\mathrm{PbO}-\mathrm{SnO}_{2}-\mathrm{SiO}_{2}$ system allows tin oxide to react forming a lead stannate intermediary phase and, if heated to sufficient temperature, to recrystallize as finer particles of cassiterite, which provide increased opacity as compared to unreacted cassiterite $[29,30]$. The higher proportion of soda-lime-silica glass and lower lead oxide content found in the white enamel, as opposed to the yellow and green, allow cassiterite recrystallization to occur at a lower temperature.

In addition, the lead oxide present in the yellow, green, and white enamel matrices acts as a flux reducing the enamels' softening temperatures: the higher the amount of lead oxide, the lower the softening temperature of the enamel $[7,29]$. Often referred to as low-fire or "soft" enamels $[10,19,31]$, these lead-rich enamels can be fired at relatively low temperatures, well below the softening temperature of the blank itself. Because the blank is unlikely to deform, "soft" enamels can be fired onto a stationary object using a kiln. Conversely, high-fire or "hard" enamels, having no or low lead oxide content, must be fired at higher temperatures and for sufficient time to allow the enamels to fully fuse. For the furnace-firing of "hard" enamels, the decorated blank is attached to a pontil rod so that it can be rotated and, in some cases, shaped at the furnace to prevent the vessel from collapsing.

Blue enamels colored by lazurite are usually described as cold-mixed due to their relatively heterogeneous 
microstructure and the presence of angular particles of sulphur-bearing sodium alumino-silicate. Here, the blue enamel matrix has a surprisingly homogeneous microstructure and, even in areas free of blue sulphur-bearing sodium alumino-silicate particles, exhibits small amounts of sulfur combined with the characteristic Raman signature associated with $\mathrm{S}_{3}{ }^{-}$and $\mathrm{S}_{2}{ }^{-}$multi-atomic ions. This suggests that a small portion of the sulfur radicals from the sulfur-bearing sodium alumino-silicate particles has diffused and solubilized into the matrix, pointing toward a pre-fritted blue enamel colored by lapis lazuli particles. Examples of solubilized sulfur radical ions have been reported in the literature: in some Della Robbia blue glazes, the presence of the $\mathrm{S}_{3}{ }^{-}$ion stretching vibration has been identified despite the fact that no inclusions are visible [32]. Pre-fritting of this type of enamel is conceivable, as lapis lazuli presents good thermal stability [33], with thermal treatment higher than $1000{ }^{\circ} \mathrm{C}$ required to degrade the color associated with the sulfur radical ions [11]. Further experimentation, particularly investigating the solubility of lazurite in soda-lime-silica glass, would be required to confirm the hypothesis that sulfur radicals have diffused and solubilized into the soda-lime-silica matrix during the firing of the frit.

The decorated blank was fired to adhere the gilding and fuse the enamels. Although the softening temperatures of the enamels differ due to their varying lead contents, Mamluk glassmakers likely applied all colors together, affixing them with a single firing. The complex pontil mark visible on the bottom of the vessel indicates that a pontil was reattached to the decorated vessel to reintroduce the object into the furnace, technology consistent with Mamluk manufacture, as opposed to stationary kiln firing not practiced until the 19th century. The apparent double, but not triple or quadruple, pontil mark on the Brooklyn Museum lamp supports the hypothesis that all decorative materials were simultaneously fired. Evidenced in the enamel samples analyzed, the lamp's red and white enamels are intimately mixed despite their differing lead contents, suggesting that these "hard" and "soft" enamels were fired together. The occurrences of decorative material contaminants in the enamels, such as the tin-rich and iron-rich inclusions identified in the blue enamel and the lazurite particle in the white enamel, also suggest simultaneous application and firing of the various decorative materials.

Gudenrath [19] has observed that some 13th-century beakers show elongated bubbles and stretched gilding and enamels, indicating that the vessel was shaped at the furnace during firing after decoration. However, Gudenrath [19] mentions that mosque lamps from the same time do not seem to share these features, remarking on the relative crookedness of many lamps. No indications of shaping during firing of the decorative materials were noted on the Brooklyn Museum's lamp, consistent with Gudenrath's observations. The discrete glass particles visible in the red enamel and the preponderance of bubbles in the red and white enamels indicate a very short firing, which would have helped maintain the shape of the body and handles.

\section{Conservation, display, and interpretation}

The analytical data and understanding of the manufacturing process gleaned through this study will aid Brooklyn Museum staff in future decisions related to the lamp's conservation treatment and display. Following the discoveries made during this study, the foot likely will not be re-attached to the lamp. When museum staffs take apart an assembled object, treatment and display decisions inherently privilege certain moments in that object's history but strive to acknowledge how the object has changed. The choice to not re-attach the foot also reflects the Brooklyn Museum's mission statement, which highlights the contextual history of museum objects rather than only their place in a chronological history.

If the foot is not re-attached to the lamp, alternative mount and support options exist for the object's display. An acrylic mount in the shape of a flared cone could physically support the object while suggesting, but not replicating, a typical Mamluk form. Fashioned from an optically clear conservation-grade resin, a replacement foot could be made to meet the break edge of the body, more closely mimicking the presumed original. A more minimal mount solution could stabilize the object as it is now, without providing any suggestion of a foot to the viewer. With a replacement foot, the lamp could conceivably be hung for display, intimating the object's original use; however, this option raises safety concerns. Additionally, the Museum's collection database will document the historical association of these two fragments; and, the foot can be reattached to the lamp if curatorial and conservation perspectives change in future.

The results of this study will also inform the interpretative materials accompanying the lamp's future display. Previous in-gallery texts (c. 1970-2012) omitted uncertainties over attribution, instead focusing on such lamps' well-known connection to the Qur'an's Sura of Light, which likens their illuminated glow to a symbol of divine light and compares God's presence to a light enclosed in a glass in a niche. Future interpretative materials can now address the different dates of the body and the foot, sharing how scientific and technical research contributes to the object's story. The detached foot may be exhibited alongside the lamp, showing visitors both how the original base might have looked and the added base itself, which was part of the object for some of its history. 


\section{Conclusions}

The results obtained from instrumental analysis point to a Mamluk (13th-14th century) origin for this fragmentary lamp, which comprises a flared body with six handles and a tubular wick-holder. The composition of the bulk glass of the foot associated with this object, however, is dissimilar, indicating its later addition to the object. This foot may have been added as a replacement for a missing or broken original. Damaged objects can be variously modified to facilitate repair, repurposing, and restoration. Fragments belonging to the same object can be altered for reconstruction. In the case of this lamp, mismatched components were ground down to facilitate the association of fragments from different objects. We can interpret these objects through the lens of the object's condition history as we receive them in the present day, or we can select moments in time to represent the object in a more holistic way, privileging the so-called moment of creation but acknowledging the object's history and changes throughout time.

The assemblage having historically complicated attribution, it is now possible to contextualize the features and manufacture of these two associated fragments. The results situate the lamp both within the corpus of Mamluk-era glass mosque lamps and within the history of collecting, both by the Museum and the lamp's previous donor-collector. This lamp in the Brooklyn Museum is an interesting example of the well-known form. Demonstrated using analytical data, the identical bulk glass composition of the lamp body and wick-holder offers compelling evidence that the wick-holder is original to the lamp. These data place the Brooklyn Museum's lamp among a small number of extant Mamluk mosque lamps known to include an integral wick-holder and supports the supposition that the use of such wick-holders in Mamluk lamps relates to the vessel's size, rather than to a technological shift. The publication of this lamp, then, introduces this object as an additional example of its type, as well as adding to the body of knowledge regarding bulk glass and enamels of Mamluk production.

\begin{abstract}
Authors' contributions
CM and LB wrote the project proposal. MW and LB spearheaded the research study. JS, VS, and CM coordinated the study and prepared the draft manuscript. JS and MG performed the in situ XRF analysis. VS assisted during the XRF acquisition with the handling of the object and reversed the past adhesive repair joining the body and the foot to enable analysis and sampling. VS and LB took the samples. JS prepared the samples as cross-sections and performed the SEM-EDS and Raman spectroscopy analyses. MG performed the LA-ICP-MS measurements. JS, MG, and MW carried out the interpretation of the analytical results. CM, VS, and LB related the analytical results to the object's curatorial and conservation interpretation. All authors read and approved the final manuscript.
\end{abstract}

\section{Author details}

${ }^{1}$ Center for Scientific Studies in the Arts, Northwestern University, 2145 Sheridan Road, Evanston, IL 60208, USA. ${ }^{2}$ Brooklyn Museum, 200 Eastern Parkway, Brooklyn, NY 11238, USA.

\section{Acknowledgements}

This collaborative initiative (2013-2018) is part of NU-ACCESS's broad portfolio of activities, made possible by generous support of the Andrew W. MelIon Foundation as well as supplemental support provided by the Materials Research Center, the Office of the Vice President for Research, the McCormick School of Engineering and Applied Science, and the Department of Materials Science and Engineering at Northwestern University. This work made use of the OMM facility and of the EPIC and SPID facilities of the NUANCE Center at Northwestern University, which has received support from the MRSEC program (NSF DMR-1121262) at the Materials Research Center, the International Institute for Nanotechnology (IIN), the Keck Foundation, and the State of Illinois, through the IIN. At the Brooklyn Museum, we thank Sarah DeSantis, Photographer and Manager of Public Imaging, for the photography of the Brooklyn Museum's lamp. We are grateful to Dr. Laure Dussubieux, scientist at the Field Museum, Chicago, for providing us access to the Field Museum facilities to perform the LA-ICP-MS analyses.

\section{Competing interests}

The authors declare that they have no competing interests.

Received: 4 September 2015 Accepted: 10 February 2016

Published online: 25 February 2016

\section{References}

1. Carboni S. Mamluk enamelled and gilded glass in the Museum of Islamic Art, Qatar. London: The Islamic Art Society; 2003.

2. Wallis R. Fact or fiction: 19th-century European interpretations of islamic decorative arts. http://pastinpresent.courtauld.ac.uk/past-in-present-v/.

3. Vernoit S. Islamic gilded and enamelled glass in nineteenth-century collections. In: Ward R, editor. Gilded and enamelled glass from the Middle East. London: British Museum Press; 1998. p. 110.

4. British Museum: Enamelled glass mosque lamp, by Philippe Joseph Brocard. http://www.britishmuseum.org/explore/highlights/highlight_ objects/pe_mla/e/enamelled_glass_mosque_lamp,_b.aspx.

5. Whitehouse D. Imitations of Islamic glass. In: Carboni S, Whitehouse D, editors. Glass of the Sultans. New York, New Haven: Metropolitan Museum of Art, Yale University Press; 2001. p. 297.

6. Henderson J, Allan J. Enamels on Ayyubid and Mamluk glass fragments. Archeomaterials. 1990;4:167-83.

7. Freestone I, Stapleton C. Composition and technology of Islamic enamelled glass of the thirteenth and fourteenth centuries. In: Ward R, editor. Gilded and enamelled glass from the Middle East. London: British Museum Press; 1998. p. 122.

8. Eremin K, Al-Khamis U: Mamluk and pseudo-Mamluk glass in the National Museums of Scotland. In: Annales du 15e Congrès de l'Association Internationale pour l'Histoire du Verre (Corning, New York, 2001). AlHV: Nottingham; 2003. p. 193-8

9. Henderson J. Technological analysis of Mamluk glass. In: Carboni S, editor. Mamluk enamelled and gilded glass in the Museum of Islamic Art, Qatar. London: The Islamic Art Society; 2003. p. 28.

10. Wypyski M. Compositional study of medieval Islamic enameled glass from the Metropolitan Museum of Art. In: Grubb N, editor. Metropolitan Museum studies in art, science and technology 1. New York: Metropolitan Museum of Art; 2010. p. 109.

11. Colomban P, Tournié A, Caggiani M, Paris C. Pigments and enameling/ gilding technology of Mamluk mosque lamps and bottle. J Raman Spectrosc. 2012:43:1975-84.

12. Dussubieux L, Robertshaw P, Glascock M. LA-ICP-MS analysis of African glass beads: laboratory inter-comparison with an emphasis on the impact of corrosion on data interpretation. Int J Mass Spectrom. 2009;284:152-61.

13. Colomban P, Tournié A, Bellot-Gurlet L. Raman identification of glassy silicates used in ceramics, glass and jewellery: a tentative differentiation guide. J Raman Spectrosc. 2006;37:841-52.

14. Burgio L, Clark R. Library of FT-Raman spectra of pigments, minerals, pigment media and varnishes, and supplement to existing library of Raman spectra of pigments of visible excitation. Spectrochim Acta Part A. 2001;57:1491-521. 
15. Froment F, Tournié $A$, Colomban P. Raman identification of natural red to yellow pigments: ochre and iron-containing ores. J Raman Spectrosc. 2008;39:560-8.

16. Bell I, Clark R, Gibbs P. Raman spectroscopic library of natural and synthetic pigments (pre- 1850 AD). Spectrochim Acta Part A Mol Biomol Spectrosc. 1997;53:2159-79.

17. Clark R, Cridland L, Kariuki B, Harris K, Withnall R. Synthesis, structural characterization and Raman spectroscopy of the inorganic pigments lead tin yellow types I and II and lead antimonate yellow: their identification on medieval paintings and manuscripts. J Chem Soc Dalton Trans. 1995;16:2577-82.

18. Pelosi P, Agresti G, Santamaria U, Mattei E. Artificial yellow pigments: production and characterization through spectroscopic methods of analysis. e-Preserv Sci. 2010;7:108-15.

19. Gudenrath W. Enameled glass vessels, 1425 B.C.E.-1800: the decorating process. J Glass Stud. 2006;48:23-70.

20. Sayre E, Smith R. Compositional categories of ancient glass. Science. 1961;133:1824-6.

21. Brill R. Some thoughts on the chemistry and technology of Islamic glass. In: Carboni S, Whitehouse D, editors. Glass of the Sultans. New York: The Metropolitan Museum of Art; 2001. p. 25.

22. Henderson J, McLoughlin S, McPhail D. Radical changes in Islamic glass technology: evidence for conservatism and experimentation with new glass recipes from early and middle Islamic Raqqa, Syria. Archaeometry. 2004;46(3):439-68.

23. Henderson J. The science and archaeology of materials. An investigation of inorganic materials. London: Routledge; 2000.

24. Carboni S. Painted glass. In: Carboni S, Whitehouse D, editors. Glass of the Sultans. New York and New Haven: Metropolitan Museum of Art and Yale University Press; 2001. p. 199.
25. The Collection Online, Mosque Lamp of Amir Ahmad al-Mihmandar. http://www.metmuseum.org/collection/the-collection-online/search/44 4713 ? rpp $=30 \& p g=1 \& \mathrm{ft}=$ mosque\%2Blamp\&pos $=10 \& \mathrm{imgno}=0 \&$ tabna me=label.

26. Gudenrath W. A survey of Islamic glassworking and glass-decorated techniques. In: Carboni S, Whitehouse D, editors. Glass of the Sultans. New York: The Metropolitan Museum of Art; 2001. p. 46.

27. Ward R. Mosque lamps and enamelled glass: getting the dates right. In: Behrens-Abouseif D, Conermann S, editors. The Arts of the Mamluks in Egypt and Syria-Evolution and Impact. Goettingen: V\&R Unipress and Bonn University Press; 2012. p. 55.

28. Kühn H. Lead-tin yellow. In: Roy A, editor. Artists' pigments: a handbook of their history and characteristics, vol. 2. Oxford: Oxford University Press; 1993. p. 83.

29. Tite M, Pradell T, Shortland A. Discovery, production and use of tin-based opacifiers in glasses, enamels and glazes from the Late Iron Age onwards: a reassessment. Archaeometry. 2008;50(1):67-84.

30. Molera J, Pradell T, Salvadó N, Vendrell-Saz M. Evidence of tin oxide recrystallization in opacified lead glazes. J Am Ceram Soc. 1999;82(10):2871-5.

31. Freestone I. The relationship between enameling on ceramics and on glass in the Islamic world. Archaeometry. 2002;44(2):251-5.

32. Sendova M, Zhelyaskov V, Scalera M, Gulliford C. Micro-Raman spectroscopy characterization of Della Robbia glazes. Archaeometry. 2007:49(4):655-64.

33. de Buffon C. Histoire Naturelle des Minéraux, Tome IV. Paris: Imprimerie Royale; 1786.

\section{Submit your manuscript to a SpringerOpen ${ }^{\circ}$ journal and benefit from:}

- Convenient online submission

- Rigorous peer review

- Immediate publication on acceptance

- Open access: articles freely available online

- High visibility within the field

- Retaining the copyright to your article

Submit your next manuscript at $>$ springeropen.com 